\title{
Improved defect control and mechanical property variation in high pressure die casting of A380 alloy by high shear melt conditioning
}

${ }^{*}$ Y. Zhang, J. B. Patel, J. Lazaro-Nebreda, and Z. Fan

Brunel Centre for Advanced Solidification Technology (BCAST), Brunel University London, Kingston Lane, Uxbridge UB8 3PH, United Kingdom

('Corresponding author: yijie.zhang@brunel.ac.uk)

\begin{abstract}
To reduce the mechanical property variation of A380 alloy produced by high pressure die casting, high shear melt conditioning (HSMC) technology was developed and applied to the melt prior to pouring into shot sleeve. Experimental results show that with application of HSMC, the variation of elongation was decreased from $21.8 \%$ to $13.9 \%$, and yield strength variation was reduced from $5.5 \%$ to $3.6 \%$. The improved property variation is attributed to enhanced nucleation both in the shot sleeve and the die-cavity, and to the improved distribution of porosity and secondary phases as a benefit of high shear induced grain refinement. With application of high shear, large number of the Spinel phase $\left(\mathrm{MgAl}_{2} \mathrm{O}_{4}\right)$ particles with double size distribution in average diameter of $80 \mathrm{~nm}$ and $300 \mathrm{~nm}$ were formed. Due to the good orientation relationship and small misfit between (alpha)- $\mathrm{Al}$ and $\mathrm{MgAl}_{2} \mathrm{O}_{4}$, the particles act as effective nuclei in shot sleeve and die cavity respectively.
\end{abstract}

\section{INTODUCTION}

A380 alloy has been widely used for production of automotive components by cold chamber high pressure die casting (HPDC) process, due to its relatively good castability and mechanical properties, and more importantly most of A380 ingots are usually produced from recycled materials [1-3]. This promotes the use of A380 alloy and contributes to reducing $\mathrm{CO}_{2}$ emissions when it comes to the lightweight in the automotive industry. When the cold chamber HPDC process is chosen to produce the automotive components, the mechanical properties of A380 alloy always have a large distribution range (named variation herein). In other words, the properties are not stable or repeatable for each component produced. The reason for this unpredictable variation is attributed to the typical solidification characteristics occurred in the HPDC process. The HPDC process can be characterized in 3 steps regards to movement on melt. The first step is that the melt is poured into the shot sleeve at a temperature of about $680^{\circ} \mathrm{C}$, in which the shot sleeve is preheated by a deliberate melt filling, or by a heating system. During this first step, solidification happens for the first time in the shot sleeve which is known to be about $20 \%$ of the melt volume and produces coarse $\alpha-\mathrm{Al}$ grains [4]. These coarse grains retain throughout the casting process and appear in the final products and are deemed to cause the unpredictable variation of mechanical properties. The second step is that the melt is forced moving forward by the plunger at about $0.2-0.3 \mathrm{~m} / \mathrm{s}$ until it approaches the inner gate of the mould. The third step is that the melt is displaced very fast by the plunger at about $3-4 \mathrm{~m} / \mathrm{s}$ to complete the filling of die cavity and refilling of the solidification shrinkage. The second solidification occurs in the die cavity and very fine $\alpha-\mathrm{Al}$ 
grains form due to a high pressure and high cooling rate of about $500-1000^{\circ} \mathrm{C} / \mathrm{s}$. From the solidification point of view, the grain size is dominated by nucleation and growth. When the HPDC process is employed to produce automotive components, the melt quality becomes the priority factor to control the solidification process in comparison to other casting parameters.

The coarse $\alpha$-Al grains formed in the shot sleeve are considered to be the main factor that affects the mechanical properties stability. To minimize the existence of the coarse grains and then reduce mechanical properties variation, various efforts have been taken, such as optimizing the filling process [5-6], increasing shot sleeve temperature and pouring temperature [7]. Indeed, these methods can reduce the variation of mechanical properties, but this improvement is achieved at the expense of shortening the lifetime of the shot sleeve and die.

Grain refinement is proven that it is the best approach to obtain the fine uniform microstructure and improve the yield strength and elongation simultaneously, and Al5Ti1B is the best grain refiner for Al alloys currently [8-10]. During producing A380 alloy components, A15Ti1B refiner was always added into melt as a necessary casting procedure. In view of the specific solidification of HPDC and the characteristics of A380 alloy, the addition of A15Ti1B refiner contributes limited improvement of mechanical properties variation.

Recently, physical refinement method by high shearing melt conditioning (HSMC) technique patented by BCAST has been proved that it can refine most $\mathrm{Mg}$ and $\mathrm{Al}$ alloys [11-14]. The refinement mechanism is that high shear can disperse the existing oxide films into fine particles as potential nuclei for $\mathrm{Mg}$ and accelerate the formation of $\mathrm{MgAl}_{2} \mathrm{O}_{4}$ as effective nuclei for $\mathrm{Al}$ alloys.

In present study, the mechanical properties variation of A380 components produced via HPDC with traditional melt processing, and with high shear melt conditioning prior to HPDC (MC-HPDC) was investigated. The mechanisms of the influence of high shear both on shot sleeve solidification and die cavity solidification are discussed.

\section{MATERIALS AND METHOD}

A380 alloy supplied by Norton was used as raw material for conducting HPDC processing, its composition mainly contained $9.35 \% \mathrm{Si}, 4.51 \% \mathrm{Cu}, 1.51 \% \mathrm{Zn}, 0.84 \% \mathrm{Fe}, 0.32 \% \mathrm{Mn}, 0.07 \% \mathrm{Mg}$ and $0.065 \% \mathrm{Ti}$ (in wt.\% percent). In the present study, clay-graphite crucible and electrical resistance furnace were used to melt alloys, and two crucibles of $50 \mathrm{Kg} \mathrm{A} 380$ ingots each were prepared for comparison of melt with and without high shear melt conditioning. When the melt temperature reached $750^{\circ} \mathrm{C}, 30$ minutes of holding time was needed to uniform the composition distribution. Then, rotary degassing and high shearing melt conditioning were employed in each crucible respectively. The parameters of rotary degassing were $350 \mathrm{rpm}$ stirring speed for 8 minutes with Ar flow rate of $4 \mathrm{~L} / \mathrm{min}$. High shear melt conditioning included two steps. The first step was degassing with Ar flow rate of $0.2 \mathrm{~L} / \mathrm{min}$ and shearing 5 minutes at rotor speed of 1500 rpm, and the second step was only shearing at $1500 \mathrm{rpm}$ for 10 minutes to complete the melt conditioning treatment without introducing Ar. After finishing melt treatment, the melt was poured into shot sleeve manually with transfer ladle, and then melt was pushed into die cavity by plunge to obtain 8 tensile test samples with $6.35 \mathrm{~mm}$ in diameter in extensometer part for each shot, in which the temperature of melt, shot sleeve and die mold was $680^{\circ} \mathrm{C}, 180^{\circ} \mathrm{C}$ and $150^{\circ} \mathrm{C}$ respectively.

After 24 hours nature ageing, the samples were tested at as-cast state by Instron 5500 Universal 
Electromechanical Testing System at an ambient temperature. The gauge length of the extensometer was 25 $\mathrm{mm}$ and the ramp rate for extension was $1 \mathrm{~mm} / \mathrm{min}$. Specimens for microstructure analysis were cut from the centre of the tensile sample bars with cross section perpendicular to tensile direction.

Pressure filtration melt cleanliness analyser (Prefil ${ }^{\circledR}$-Footprinter) was also used after finishing melt treatment (with and without HSMC) to collect the particles in the melt. Then, the samples were cut perpendicular to the filtration direction to obtain the sample for microstructure observation at filter and melt interface. Samples for metallographic examination were prepared by a standard technique. Field-emission scanning electron microscopy (FE-SEM, SUPRA 35VP, Carl-Zeiss Company) equipped with an energy dispersive X-ray spectroscopy (EDS) was used for microstructure analysis.

\section{RESULTS AND DISCUSSION}

Fig. 1 shows the yield strength and elongation of the A380 alloy HPDC tensile samples after rotary degassing and high shear melt conditioning. The distribution range of yield strength and elongation of A380 alloy with rotary degassing was from $129.1 \mathrm{MPa}$ to $152.9 \mathrm{MPa}$, and from $2.91 \%$ to $6.88 \%$ respectively. With application of high shear melt conditioning, the distribution range of yield strength and elongation was from $130.7 \mathrm{MPa}$ to $149.9 \mathrm{MPa}$, and from $3.73 \%$ to $6.62 \%$ respectively.

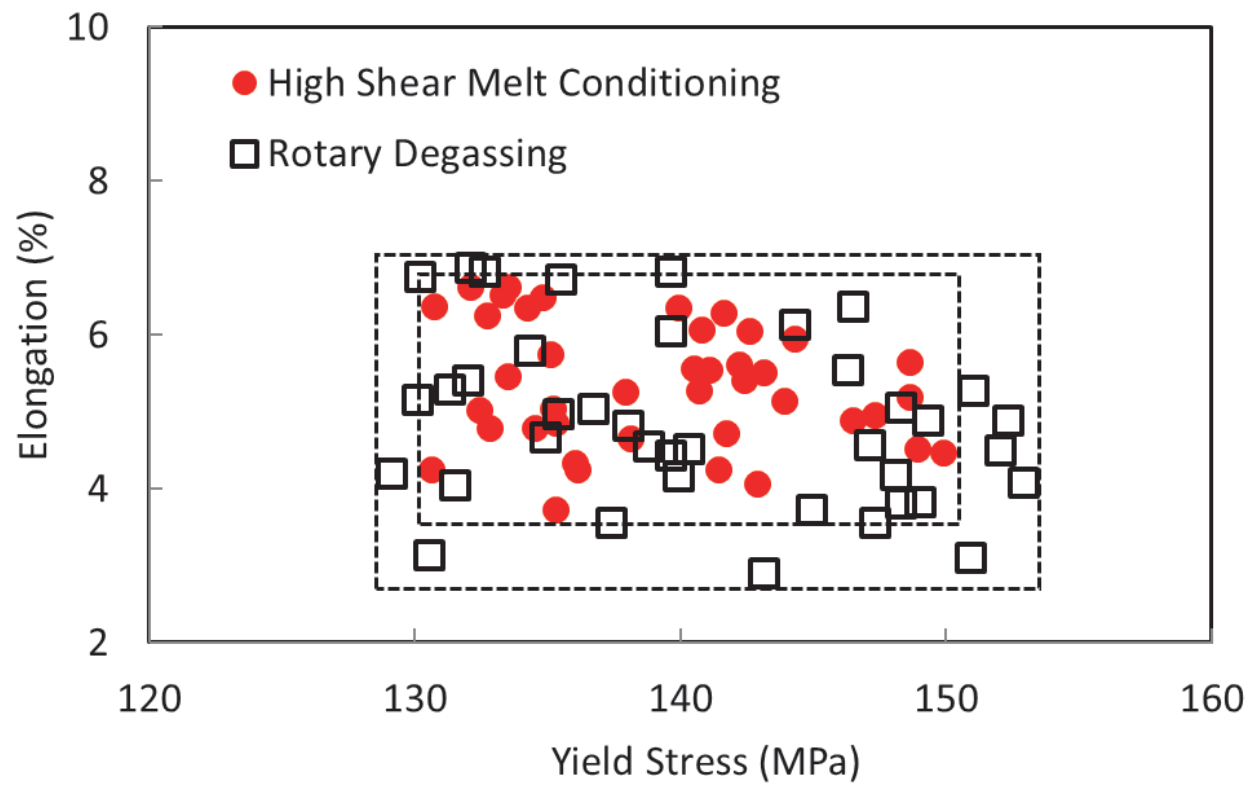

Fig.1. The comparison of mechanical properties of A380 alloys between rotary degassing and high shear melt conditioning showed that melt treatment with high shear can improve the variation both on yield strength and elongation

It can be seen from the comparison that high shear melt conditioning can reduce the variation of both yield strength and elongation. To obtain the coefficient of variation (CV), the equation of $\mathrm{CV}=\mathrm{SD} / \mu * 100 \%$ is used, in which SD is standard deviation and $\mu$ is the average value of yield strength or elongation. The small value of $\mathrm{CV}$ means the narrow distribution range of properties and the good property stability. The 
influence of high shearing melt conditioning on the coefficient of variation of A380 alloy was shown in table 1. The data in table 1 revealed that with high shearing treatment, yield strength variation was decreased from $5.48 \%$ to $3.62 \%$, and elongation variation was decreased from $21.83 \%$ to $13.96 \%$. The variation comparison indicated that high shear melt conditioning can improve the mechanical properties variation.

Table 1. Coefficient of variation of yield strength and elongation of A380 alloys with melt treatment of rotary degassing and high shear respectively

\begin{tabular}{|c|c|c|c|c|c|c|}
\hline \multirow[b]{2}{*}{ Melt treatment } & \multicolumn{2}{|c|}{ Average value $(\mu)$} & \multicolumn{2}{|c|}{ Standard Deviation (SD) } & \multicolumn{2}{|c|}{ Coefficient of Variation(CV) } \\
\hline & $\begin{array}{c}\text { Yield strength } \\
(\mathrm{MPa})\end{array}$ & $\begin{array}{c}\text { Elongation } \\
(\%)\end{array}$ & $\begin{array}{l}\text { Yield strength } \\
(\mathrm{MPa})\end{array}$ & $\begin{array}{c}\text { Elongation } \\
(\%)\end{array}$ & $\begin{array}{c}\text { Yield strength } \\
(\%)\end{array}$ & $\begin{array}{c}\text { Elongation } \\
(\%)\end{array}$ \\
\hline Rotary degassing & 141.10 & 4.90 & 7.74 & 1.06 & 5.48 & 21.83 \\
\hline HSMC & 139.30 & 5.40 & 5.04 & 0.75 & 3.62 & 13.96 \\
\hline
\end{tabular}

To investigate the mechanism of variation improvement, observation of microstructure evolution was necessary to reveal the grain refinement performance, secondary phase distribution and porosity distribution and so on. Fig. 2 shows the grain morphology of $\alpha$-Al formed in the shot sleeve $\left(\alpha-\mathrm{Al}_{1}\right)$ and in the die cavity $\left(\alpha-\mathrm{Al}_{2}\right)$ of A380 alloy with rotary degassing (Fig. 2a) and with high shear melt conditioning (Fig. 2b). $\alpha$ - $\mathrm{Al}_{1}$ grains formed in shot sleeve are normally coarse due to the relative slow cooling rate and more growth time after nucleation and $\alpha-\mathrm{Al}_{2}$ grains formed in die cavity are finer because of the high cooling rate. With rotary degassing the size of the coarse $\alpha-\mathrm{Al}_{1}$ grains was about $50 \mu \mathrm{m}$, and the size of $\alpha-\mathrm{Al}_{2}$ grains was about $10 \mu \mathrm{m}$. After application of high shear melt conditioning, both the size of coarse $\alpha-\mathrm{Al}_{1}$ grains and fine $\alpha-\mathrm{Al}_{2}$ grains was reduced to about $30 \mu \mathrm{m}$ for $\alpha-\mathrm{Al}_{1}$ grains and $5 \mu \mathrm{m}$ for $\alpha-\mathrm{Al}_{2}$ grains. More importantly, the size distribution of $\alpha$-Al grains was more uniform than that of microstructure without high shear application.
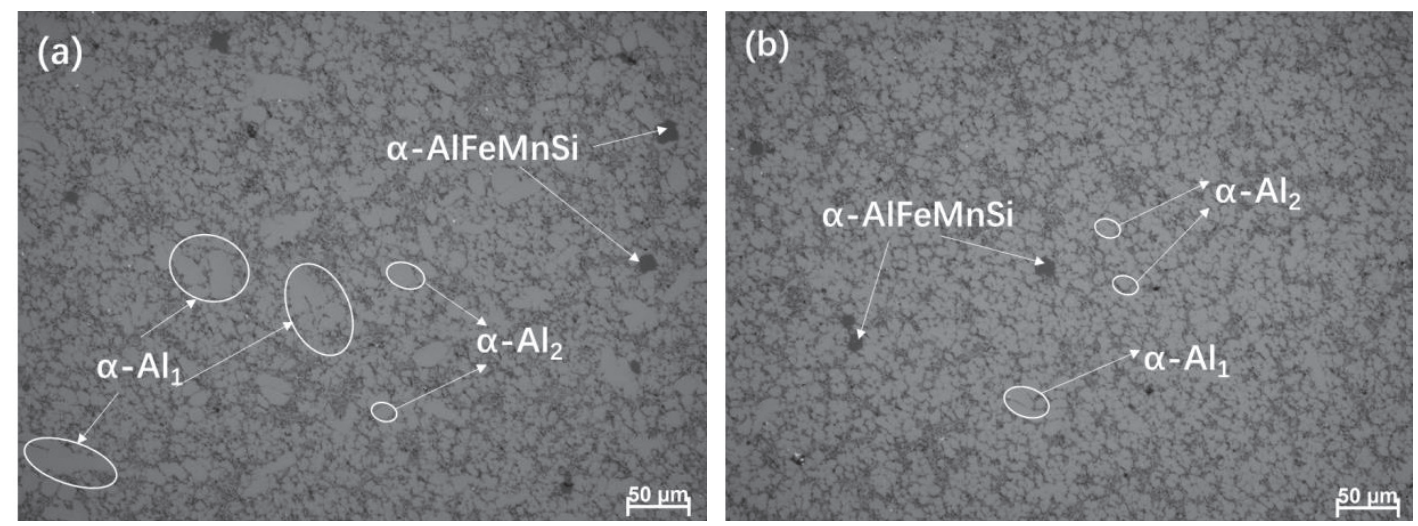

Fig. 2. Grain morphology of A380 alloys showed that better grain refinement and uniform grain distribution were achieved with high shear melt conditioning (b) compared to the microstructure without high shearing (a), and the size of $\alpha$-Al formed in shot sleeve $\left(\alpha-\mathrm{Al}_{1}\right)$ was decreased significantly with high shearing 
The refinement of $\alpha$-Al both formed in shot sleeve and die cavity illustrated that high shear melt conditioning can promote the nucleation performance of A380 alloy. Spinel $\left(\mathrm{MgAl}_{2} \mathrm{O}_{4}\right)$ was revealed that it can be the effective nucleation site for $\alpha-\mathrm{Al}$ in $\mathrm{Al}-\mathrm{Mg}$ alloy $[7,13]$ and in $\mathrm{Al}$ alloy $[8,15]$ due to the small misfit of about $1.4 \%$ between spinel and Al. Basing on the relationship between undercooling and nuclei size, to activate the spinel as effective nuclei, the size distribution of particles became the important factor to dominant the spinel performance on grain refinement of $\mathrm{Al}$ alloy produced by HPDC processing.

The particles in A380 alloys were analyzed using SEM after collecting via Prefil ${ }^{\circledR}$-Footprinter and the results were shown in fig.3. It can be seen from fig. 3a that $\mathrm{TiB}_{2}$ was the main particle type in $\mathrm{A} 380$ alloy with rotary degassing, and its size was about or more than $1 \mu \mathrm{m}$. These $\mathrm{TiB}_{2}$ particles were from the retained $\mathrm{TiB}_{2}$ particles added as refiner in recycled Al. Fig. $3 \mathrm{~b}$ showed that besides $\mathrm{TiB}_{2}$ particles, $\mathrm{MgAl}_{2} \mathrm{O}_{4}$ with two kinds of size distribution were found in A380 alloy with high shear melt conditioning. The size of relative big $\mathrm{MgAl}_{2} \mathrm{O}_{4}$ particles was about $300 \mathrm{~nm}$, and the size of small particles was about $80 \mathrm{~nm}$. The existence of $\mathrm{MgAl}_{2} \mathrm{O}_{4}$ indicated that high shear can promote the formation of such phases. The formation mechanism of $\mathrm{MgAl}_{2} \mathrm{O}_{4}$ can attributed to the disperse effect of high shear on existing $\mathrm{Al}_{2} \mathrm{O}_{3}$ film in $\mathrm{Al}$ melt. There always have many $\mathrm{Al}_{2} \mathrm{O}_{3}$ film in melt due to the disturbance of melt surface and the active reaction between $\mathrm{Al}$ and $\mathrm{O}_{2}$. During high shear unit running, the melt was forced into the shearing area with a shear rate of about $10^{5}$ $10^{6} \mathrm{~s}^{-1}$ and any oxide films into these area would be breakup into fine particles. If the melt contains $\mathrm{Mg}$, the reaction between dispersed $\mathrm{Al}_{2} \mathrm{O}_{3}$ particles and $\mathrm{Mg}$ would occur and then form $\mathrm{MgAl}_{2} \mathrm{O}_{4}$.
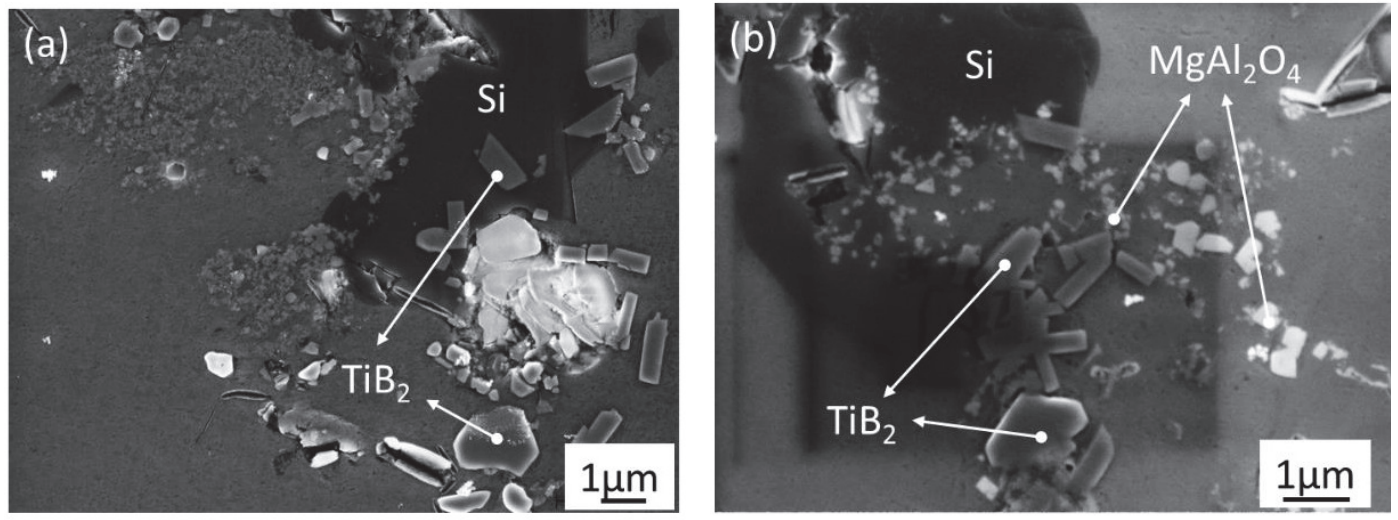

Fig. 3. Microstructure of prefil samples showed that $\mathrm{TiB}_{2}$ was the main type of particles in $\mathrm{A} 380$ alloy with rotary degassing (Fig.3a), and $\mathrm{MgAl}_{2} \mathrm{O}_{4}$ and $\mathrm{TiB}_{2}$ were the main kinds of particles in $\mathrm{A} 380$ alloy with high shear melt conditioning (Fig.3b)

\section{CONCLUSIONS}

High shear melt conditioning can reduce the variation of yield strength and elongation of HPDC A380 alloy. With MC-HPDC, the coefficient of variation of elongation was decreased from $21.8 \%$ to $13.9 \%$, and yield strength variation coefficient was reduced from $5.5 \%$ to $3.6 \%$. The improved property variation is attributed to enhanced nucleation both in shot sleeve and the die cavity caused by formation of $\mathrm{MgAl}_{2} \mathrm{O}_{4}$ particles, in which double size distribution of about $80 \mathrm{~nm}$ and $300 \mathrm{~nm}$ were synthesized. The grain refinement 
principle was ascribed to the good orientation relationship and small misfit between $\alpha-\mathrm{Al}$ and $\mathrm{MgAl}_{2} \mathrm{O}_{4}$.

\section{ACKNOWLEDGMENTS}

This project is financially supported by EPSRC UK in the EPSRC Centre for Innovative Manufacturing in Liquid Metal Engineering (The EPSRC Centre-LiME).

\section{REFERENCES}

[1] A. Fabrizi, S. Ferraro, G. Timelli, Mater. Charact., 85, 13 (2013).

[2] H. Yang, S. Ji, Z. Fan, Mater. Des., 85, 823 (2015).

[3] S. Seifeddine, I.L. Svensson, Metall. Sci. Technol., 27, 11 (2009).

[4] X. Li, S.M. Xiong, Z. Guo, J. Mater. Process. Technol., 231, 1 (2016).

[5] B.H. Hu, K.K. Tong, X.P. Niu, I. Pinwill, J. Mater. Process. Technol., 105, 128 (2000).

[6] D.R. Gunasegaram, M. Givord, R.G. O’Donnell, B.R. Finnin, Mater. Sci. Eng. A., 559, 276 (2013).

[7] S.L. dos Santos, R.A. Antunes, S.F. Santos, Mater. Des., 88, 1071 (2015).

[8] T.E. Quested, A.T. Dinsdale, A.L. Greer, Acta Mater., 53, 1323 (2005).

[9] T.E. Quested, A.L. Greer, Acta Mater., 52, 3859 (2004).

[10] M.A. Easton, D.H. Stjohn, Acta Mater., 49, 1867 (2001).

[11] Z. Fan, Y. Wang, M. Xia, S. Arumuganathar, Acta Mater., 57, 4891 (2009).

[12] H.T. Li, M. Xia, P. Jarry, G.M. Scamans, Z. Fan, J. Cryst. Growth., 314, 285 (2011).

[13] H.T. Li, Y. Wang, Z. Fan, Acta Mater., 60, 1528 (2012).

[14] R. Haghayeghi, E.J. Zoqui, D.G. Eskin, H. Bahai, J. Alloys Compd., 485, 807 (2009).

[15] D. Zhang, L. Wang, M. Xia, N. Hari Babu, J.G. Li, Mater. Charact., 119, 92 (2016) 